\title{
INFANCIA, ADOLESCENCIA, DELITO Y SISTEMA PENAL EN ARGENTINA*
}

\author{
CHILDHOOD, ADOLESCENCE, CRIME \\ AND CRIMINAL JUSTICE SYSTEM IN \\ ARGENTINA
}

INFÂNCIA, ADOLESCÊNCIA, CRIME, E SISTEMA PENAL NA ARGENTINA

\section{RESUMEN}

En el sistema tradicional de Justicia Juvenil en Argentina, el juez desempeña un papel pasivo, ya que simplemente impone la medida correctiva o dispositiva pertinente. Este sistema no hace nada para la prevención en el problema de la delincuencia juvenil, como para evitar que se cometa nuevamente algún delito no violento.

\footnotetext{
* Articulo asociado al proyecto de investigación terminada en derecho penal con el cual se pretende enriquecer el conocimiento de la justicia aplicada a menores adolescentes en conflicto con la Ley penal.

a. Abogado y Procurador, títulos conferidos por la U. Nac. de Córdoba; Juez de la Cámara Civil, Comercial y Minería, sala II, de San Juan; Mediador, título otorgado por la Escuela Argentina de Mediación; Especialista en Derecho Procesal, con mención en Procesal Civil, título otorgado por la U.C.Cuyo; Miembro y delegado por San Juan en la Asociación Argentina de Derecho Procesal; Ponente y Expositor en distintos Congresos Nacionales de Derecho Procesal; Presidente del Colegio de Magistrados y Funcionarios del Poder Judicial de San Juan; Ex Director de la Escuela de Capacitación Judicial del Poder Judicial de San Juan; Profesor en la Cátedra de Derecho Procesal I y II en la
} 
Un cambio de esta realidad se daría con la creación de Tribunales de Adolescentes, dedicados a tratar las causas que motivan la comisión de delitos por los mismos, y fijar las penas por sus pares. Este sistema, de ser implementado, le permitirá al Juez ejercer un papel resocializador, dando una "segunda" oportunidad al menor.

Los tribunales de adolescentes se desarrollaron en los Estados Unidos de América como una alternativa a los tribunales tradicionales del sistema de justicia juvenil, con el propósito de dar a los jóvenes, que cometen actos delictivos menos serios, una "segunda" oportunidad.

Estos tribunales operan sobre la premisa de que al ser juzgado por sus pares, en adolescentes este hecho puede tener un impacto más grande que el ser juzgados por la figura adulta de un Juez del sistema tradicional.

\title{
PALABRAS CLAVE
}

Justicia Juvenil, las ventajas de la creación de Tribunales de Adolescentes.

\begin{abstract}
In the traditional juvenile justice system in Argentina, the judge plays a passive role and simply impose the remedies or relevant operative. This system does nothing to prevent the problem of juvenile delinquency, to prevent the commission of a nonviolent offense again.
\end{abstract}

A change of this reality would by creating Teen Courts, dedicated to addressing the causes for the commission of crimes by them and fix the penalties for their peers. This system, if implemented, will allow the Court to exercise a role re-socializing, giving a "second" chance the child.

The teen courts were developed in the United States as an alternative to traditional courts juvenile justice system, with the purpose of giving young people who commit serious criminal acts unless a "second" chance.

These courts operate on the premise that being judged by their peers, adolescents can have a bigger impact than being judged by the adult figures in a Judge of the traditional system.

\section{KEYWORDS}

Juvenile Justice, the advantages of creating Teen Courts.

U.C.Cuyo; Profesor en el Curso de Postgrado en Derecho Procesal Civil de la U.C.Cuyo; Miembro Titular del Instituto Panamericano de Derecho Procesal; Miembro de la Asociación Iberoamericana de Derecho Privado; Miembro de Red Latinoamericana de Jueces (REDLAJ); Miembro Titular del Instituto Cuyano -Secretaría San Juan- de la Academia de Derecho y Ciencias Sociales de Córdoba; Director del Instituto de Estudios Judiciales de la Federación Argentina de la magistratura y la Función Judicial (FAMyFJ); Miembro de AIDA (Association Internationale de Droit des Assurances) y Asociación Argentina de Derecho de Seguros Rama Nacional de A.I.D.A; Libros y Artículos publicados en Argentina y en el Extranjero. 


\section{RESUMO}

No sistema tradicional de Justiça Juvenil na Argentina, o juiz desempenha um papel passivo, porque simplesmente impõe a medida corretiva ou dispositiva pertinente. Este sistema não faz nada para prevenir no problema da delinquência juvenil, como para evitar que se cometa algum crime não violento.

Uma mudança desta realidade se daria com a criação de Tribunais de Adolescentes, dedicados a tratar as causas que motivam a comissão de delitos pelos mesmos e fixar as penas pelos pares. Este sistema, se for implementado permitirá ao juiz exercer um papel resocializado, dando uma "segunda" chance ao menor.

Os tribunais de adolescentes se desenvolveram nos Estados Unidos de América como uma alternativa aos tribunais tradicionais do sistema de justiça juvenil, com o propósito de dar aos jovens que cometem atos delituosos menos sérios uma "segunda" chance.

Estes tribunais operam sobre a premissa que ao ser julgado pelos pares, em adolescentes, este fato pode ter um impacto maior que ao ser julgados pela figura adulta de um juiz do sistema tradicional.

\section{PALAVRAS-CHAVE}

Justiça Juvenil, as vantagens da criação de Tribunais de Adolescentes.

\section{INTRODUCCIÓN}

Existe la obligación de los Estados partes de la Convención sobre los Derechos del Niño, de dotarse de una política general de justicia penal juvenil que incluya la prevención de la delincuencia juvenil. Y aun cuando los adolescentes han incurrido en la comisión de una infracción a la ley penal, si se interviene a tiempo, su recuperación -procurando su integración social- se da en una proporción superior a la de los infractores mayores de edad.

Las personas menores de edad deben ser excluidas del régimen penal de adultos, y por ende deben contar con un sistema especializado con normas y procedimientos diferentes al de los adultos transgresores, con jueces y funcionarios especialmente capacitados en cuestiones relativas a los derechos de niños y adolescentes, con competencia específica para intervenir cuando los delitos sean cometidos por personas menores de dieciocho años de edad, y se requiere además la implementación de unidades especializadas en la policía.

Se debe seguir avanzando en la construcción de un sistema especializado de justicia penal juvenil, en los términos que para ello establecen los instrumentos nacionales e internacionales de derechos humanos, de aplicación a las personas adolescentes en conflicto con la ley penal, como en las distintas formas de ejecución de las sanciones penales juveniles para la cimentación de la responsabilidad penal de la persona adolescente y, principalmente, en la realización del principio educativo con perspectivas de inclusión social. 
A ello se debe agregar que el uso de mecanismos que favorezcan vías alternativas al proceso penal, debe ser promovido para evitar el grave deterioro, y la estigmatización que suele producir un proceso penal en un adolescente.

El sistema de Justicia de menores está en proceso de cambio $\left(^{1}\right),\left({ }^{2}\right)$, y ello se constituye en objeto de esta investigación. Encontramos distintos sistemas en el derecho comparado latinoamericano, y en las provincias argentinas que han avanzado, en el sentido referido precedentemente, y otros que deben comenzar con los cambios necesarios $\left(^{3}\right)\left(\left(^{4}\right)\left({ }^{5}\right)\left({ }^{6}\right)\left({ }^{7}\right)\left({ }^{8}\right)\left({ }^{9}\right)\right.$ $\left({ }^{10}\right)\left({ }^{11}\right)$.

En conclusión, entendemos que la jurisdicción especializada para adolescentes en conflicto con la ley, así como sus leyes y procedimientos correspondientes, deben caracterizarse por dar la posibilidad de adoptar medidas para tratar en ciertos casos a esos adolescentes, sin recurrir a los procedimientos judiciales tradicionales, por lo que nos interesa analizar el sistema penal juvenil en Argentina, y especialmente en la provincia de San Juan, como el desarrollo de la denominada "Justicia Restaurativa", que permite el abordaje del conflicto penal sin judicializarlo, y de las acciones educativas que la deben complementar con el fin de que los jóvenes infractores adquieran las habilidades que les permitan integrarse y sentirse útiles a la sociedad, a los fines de exponer una propuesta al respecto.

\footnotetext{
1. QUINN, Mae C.; "Introduction: Evolving Standards in Juvenile Justice from Gault to Graham and Beyond", 38 Wash. U. J. L. E Pol'y (2012). Disponible en: $h$ ttp://digitalcommons.law.wustl.edu/wujlp/vol38/issi/2.

2. La promoción y protección de los derechos del niño es uno de los objetivos de la UE, en la que el Tratado de Lisboa ha puesto mayor énfasis. En particular, el artículo 3 (3) del Tratado de la Unión Europea exige explícitamente que la Unión Europea promueva la protección de los derechos del niño. Los derechos del niño están además consagrados en la Carta de Derechos Fundamentales de la Unión Europea. El artículo 24 de la Carta reconoce que los niños son titulares independientes y autónomas de los derechos. También hace que se promueva el interés superior del niño en la consideración primordial para las autoridades públicas e instituciones privadas.

3. La ley de infancia y adolescencia en Colombia (Ley 1098 del año 2006) tiene un capítulo de responsabilidad penal. Se trabaja con el mismo procedimiento que para adultos, pero con jueces de conocimiento y garantías especializados para el tema, y la segunda instancia del juez de garantías es una sala mixta que conforman dos magistrados de la sala de familia y uno de la sala penal de los tribunales superiores de distrito.

4. La Ley de Menores de Puerto Rico (Ley Núm. 88 de 9 de Julio de 1986 y sus enmiendas) es la que utiliza las Salas de Menores (Teen Court). Esta Ley define las faltas (delitos en adultos) y el procesamiento criminal especial de los menores para bienestar y protección de los derechos del menor, así como de la sociedad.

5. En Uruguay se ha creado una jurisdicción especializada en adolescentes en infracción a la Ley (de 13 a 17 años inclusive). El procedimiento está regulado en los capítulos IX y X del Código de la Niñez y Adolescencia Ver en http://www.ces.edu.uy/ces/index. php?option=com_contentEview $=$ article $\mathcal{E} i d=762 \mathcal{E}$ Itemid $=78$.

6. Paraguay tiene una jurisdicción especializada de menores infractores a la ley (de 14 a 17 años), se encuentra regulado en el libro $\checkmark$ del Código de la Niñez y Adolescencia.

7. En Brasil, también existe una jurisdicción especializada de menores, regulada por lo "Estatuto da Criança e do Adolescente (ver en http://www.planalto.gov.br/ccivil_03/leis/L8069.htm).

8. La Ley de Responsabilidad Penal Adolescente chilena (Ley 20084 del año 2005), establece un sistema de responsabilidad de los adolescentes por infracciones a la ley penal.

9. Dos decisiones tomadas por la Corte Suprema de Justicia de Costa Rica, traerán grandes repercusiones para la Especialización de la Justicia Penal Juvenil y constituyen un avance fundamental en la perspectiva de que el Estado cuente con una política pública en esta materia. La primera es la aprobación de "La Política de Acceso a la Justicia en Penal Juvenil", el 14 de febrero de 2011 y la segunda es lo aprobado en la sesión ordinaria de la Corte plena del 4 de junio de 2012, al dar pasos definitivos hacia la especialización de los jueces penales juveniles en todo el país.

10. "Adolescentes en el Sistema Penal. Situación actual y propuestas para un proceso de transformación". Publicación, UNICEF Arg. , SINNAF y Univ. Nac. Tres de Febrero (Bs. As. Septiembre de 2008). Disponible en: http://www.unicef.org/argentina/spanish/ Adolescentes_en_el_sistema_penal.pdf

11. Ley del Código del Niño, Niña y Adolescente. República de Bolivia .Ley № 2026 del 27 octubre 1999. Disponible en: www.unicef. org/bolivia/.../legislation_2007.htm.
} 


\section{PROBLEMA DE INVESTIGACIÓN}

Consiste en "El tratamiento de los niños, niñas y adolescentes en conflicto con la ley penal". Y tal como se indicó: "El presente artículo es resultado de un proyecto de investigación en derecho penal, en ejecución con el cual se pretende enriquecer el conocimiento de la justicia aplicada a menores adolescentes en conflicto con la Ley penal".

\section{METODOLOGÍA}

Se utilizó como método de investigación la estrategia o procedimiento heurístico (Horst Müler), y la comparación de legislaciones vigentes referidas al problema de investigación, que es el de los "niños, niñas y adolescentes en conflicto con la ley penal".

\section{RESULTADOS}

La jurisdicción especializada para adolescentes en conflicto con la ley, así como sus leyes y procedimientos correspondientes, deben caracterizarse por dar la posibilidad de adoptar medidas para tratar en ciertos casos a esos adolescentes, sin recurrir a los procedimientos judiciales tradicionales. El desarrollo de la denominada "Justicia Restaurativa" permite el abordaje del conflicto penal sin judicializarlo, y las acciones educativas la deben complementar con el fin de que los jóvenes infractores adquieran las habilidades que les permitan integrarse y sentirse útiles a la sociedad, a los fines de exponer una propuesta al respecto.

\section{EL SISTEMA PENAL JUVENIL EN ARGENTINA}

\subsection{EL SISTEMA TRADICIONAL DE LA JUSTICIA PENAL JUVENIL}

Durante los ochenta y seis años de vigencia de la Ley $\mathrm{N}^{\circ} 10.903\left({ }^{12}\right)$ de Patronato de Menores, conocida como "Ley Agote", se tendía a ver en el adolescente infractor a un sujeto destinatario de un tratamiento psicoterapéutico compulsivo.

El sistema se caracterizaba por la intervención de 'oficio' en todos aquellos casos en que se advirtieran situaciones de 'abandono moral o material', sin darse una definición clara o taxativa de lo que debía entenderse por "abandono moral" o "abandono material". La infancia se dividía entre los menores infractores o pobres, abandonados e incompatibles con las instituciones de la época, y los niños socialmente adaptados.

El Estado debía asumir la tutela de los niños en situación de carencia o infracción, institucionalizándolos en establecimientos destinados para tal fin. Los niños en peligro material o moral y aquellos acusados de cometer un delito no tenían garantías de defensa, y se consideraba a la infancia como incapaz para ejercer sus derechos $\left({ }^{13}\right)$.

12. B.O. del 27/o9/1919.

13. DE LA IGLESIA, Matilde; VELÁZQUEZ, María Eugenia; PIEKARZ, Walter; "DEVENIR DE UN CAMBIO: DEL PATRONATO DE MENORES A LA PROTECCIÓN INTEGRAL DE LOS DERECHOS DE NIÑOS, NIÑAS Y ADOLESCENTES”, FACULTAD DE PSICOLOGÍA - UBA / SECRETARÍA DE INVESTIGACIONES / ANUARIO DE INVESTIGACIONES / VOLUMEN XV. Disponible en: http://www.scielo.org.ar/pdf/anuinv/v15/v15a32.pdf. 
Nuestra Corte Federal señaló que la justicia de menores históricamente se ha caracterizado por un retaceo de principios básicos y elementales que se erige en todo debido proceso, tales como el de legalidad, culpabilidad, presunción de inocencia, proporcionalidad y defensa en juicio $\left({ }^{14}\right)$.

\subsection{EL SISTEMA DEL DECRETO LEY 22.278 (Y SU MODIFICATORIA No 22.803) - RÉGIMEN PENAL DE LA MINORIDAD.}

En Argentina, a los menores de dieciocho (18) años de edad considerados infractores a la ley penal, se les aplica las disposiciones del decreto-Ley $22.278\left({ }^{15}\right)$, donde se establece un sistema "tutelar" que se caracteriza por otorgar gran poder discrecional para el juez de menores, quien luego de haberse establecido la responsabilidad penal del menor respecto en el hecho investigado, está facultado para absolverlo, para aplicarle una pena disminuida, en la escala de la tentativa, e incluso cuando el menor no haya tenido ninguna vinculación con el hecho investigado puede disponer definitivamente de él, para el supuesto de que considere que se encuentra en un estado de abandono, peligro material o moral.

Se sostiene que ley no ha establecido una línea divisoria clara entre el niño imputado de un delito, el niño desamparado y el niño víctima de un delito.

Los menores de dieciséis (16) años pueden ser sancionados con la privación de su libertad sin mayor requerimiento que el criterio de los jueces, y sin un proceso judicial en el que se haya permitido defenderse, al poder ordenarse su internación en instituciones públicas o privadas cuando se hallaren "abandonados, faltos de asistencia, en peligro material o moral, o presenten problemas de conducta", lo cual ha sido considerado inconstitucional $\left({ }^{16}\right)\left({ }^{17}\right)$. A los menores se los puede tener "privados" de la libertad hasta los veintiún (21) años, cuando de los estudios realizados se advierta que el menor se halla en abandono, falto de asistencia, en peligro material o moral, presenta problemas de conducta, con o sin internación (art. 1 pár. 2 y 3 y art. 3 último párrafo), y cuando tienen entre 16 y 18 años se les pude aplicar la misma pena establecida para el adulto, lo cual también se ha considerado inconstitucional.

La Corte Federal ha criticado diferentes aspectos de esta normativa, indicando que nunca se distinguió entre el niño imputado de un delito y el desamparado o víctima; como que se ha manejado con eufemismos al considerar, por ejemplo, como "dispuestos", "internados", "reeducados" o "sujetos a medidas tutelares" a niños que materialmente eran sometidos a encierro $\left({ }^{18}\right)$.

También se sostuvo que otra característica no menos censurable de la justicia penal de menores es que se señala que los menores no son, por su condición, sujetos de medidas

14. C.S.J.N., "Recurso de hecho deducido por el defensor oficial de Daniel Enrique Maldonado en la causa Maldonado, Daniel Enrique y otros/ robo agravado por el uso de armas en concurso real con homicidio calificado — causa $N^{\circ} 1174-"$ ", o7/12/2005.

15. B.O. del $28 / 08 / 1980$

16. Cámara Nacional de Apelaciones en lo Criminal y Correccional Federal de la Capital Federal, Causa $N^{\circ}$ 39.520, caratulada "Incidente de Incompetencia en autos: G.F.D. y O.S. s/ expediente tutelar", del 6 de diciembre de 2006.

17. Cámara Nacional de Casación Penal. Sala III, Causa ${ }^{\circ} 7537$ caratulada “García Méndez, Emilio y Musa, Laura Cristina s/ recurso de casación", del 11 de diciembre 2007.

18. C.S.J.N., Fallos 328:4343, "M., D. E", resuelto el 7/12/o5. 
cautelares tales como la prisión preventiva, ni tampoco privados de su libertad, sino que ellos son "dispuestos", "internados" o "reeducados" o "sujetos de medidas tutelares" $\left({ }^{19}\right)$.

Para cambiar dicha realidad se indica que la legislación de niños, niñas y adolescentes no puede olvidar que es parte del ordenamiento jurídico de un Estado de Derecho y que, como tal, debe brindar las garantías y límites al ejercicio del poder punitivo de las agencias administrativas y judiciales $\left({ }^{20}\right)\left({ }^{21}\right)$.

\subsection{EL SISTEMA DE LA LEY NACIONAL DE PROTECCIÓN INTEGRAL DE LOS DERECHOS DE LAS NIÑAS, NIÑOS Y ADOLESCENTES $\mathrm{N}^{\circ} 26.061\left({ }^{22}\right)$}

Conforme lo establecido en el art. $1^{\circ}$ de la ley 26.061, la norma tiene por objeto la protección integral de los derechos de las niñas, niños y adolescentes que se encuentren en el territorio de la República Argentina, para garantizar el ejercicio y disfrute pleno, efectivo y permanente de aquellos reconocidos en el ordenamiento jurídico nacional, y en los tratados internacionales en los que la Nación sea parte.

Con la sanción y aplicación de esta ley, los niños, niñas y adolescentes dejan de ser entendidos como objetos bajo la tutela del Estado, para pasar a ser reconocidos como sujetos de pleno derecho, lo que también debe implicar su consideración como sujeto responsable.

Se indica que el principal objetivo de las políticas implementadas por la Secretaría Nacional de Niñez, Adolescencia y Familia, organismo del Poder Ejecutivo Nacional especializado en infancia y familia, y del Consejo Federal de Niñez, Adolescencia y Familia, órgano deliberativo, consultivo y planificador de políticas públicas para la infancia y la adolescencia en todo el territorio, teniendo en cuenta y trabajando desde las distintas realidades del país, consiste en fortalecer a la familia, entendiéndola como base para un desarrollo humano sustentable, y como espacio afectivo fundamental para el crecimiento de niños y niñas $\left({ }^{23}\right)$.

La norma (art. 27) establece que se deberá garantizar en todo procedimiento administrativo o judicial en el que se vea afectado un niño/niña y/o adolescente, el derecho a ser oído por la autoridad competente, que su opinión sea tomada primordialmente en cuenta al tomar una decisión que lo o la afecte; a ser asistido/da por un abogado defensor especializado en niñez y adolescencia desde el inicio del proceso, el cual será provisto en forma gratuita cuando el o la adolescente carezcan de recursos económicos, además del derecho a recurrir ante una autoridad superior toda decisión que lo afecte.

19. C.S.J.N., Fallo citado en nota 11.

2o. ZAFFARONI, Eugenio Raúl - ALAGIA, Alejandro - SLOKAR, Alejandro; “Derecho Penal, Parte General”, Editorial Ediar, Buenos Aires, 2003, p. 187.

21. La Comisión interamericana determinó que: "el Estado de Argentina es responsable internacionalmente por mantener en vigencia un sistema de justicia adolescente que permite que éstos sean tratados al igual que los adultos infractores". Cfr. informe 172/10, en la causa 12.561 caratulada: "César Alberto Mendoza y otros"

22. B.O. del 26/10/05.

23. Información disponible en: http:// wnw.desarrollosocial.gov.ar/ ninez/139 


\subsection{CÓDIGO PROCESAL PENAL DE SAN JUAN}

La ley $\mathrm{N}^{0} 7338$, específica en materia de niñez y adolescencia, prevé que se aplican todas las disposiciones del Código Procesal Penal que no sean incompatibles con ella. Dicho Código regula la "Suspensión del juicio a prueba" en los artículos 521 a 525, y conforme lo establecido en el art. 227 de la ley 7338: "Los institutos procesales de suspensión de juicio a prueba y juicio abreviado, serán de aplicación en el proceso penal de niños y adolescentes, debiendo observarse en su tramitación las normas establecidas en el Código Procesal Penal de la Provincia, siempre que no contravengan las disposiciones especiales de la presente ley".

Por Ley No 7889 se adhiere en todos sus términos a la Ley Nº 26.061 (Sistema de Protección Integral de los Derechos de los Niños, Niñas y Adolescentes). Y con el dictado de la Ley No 8194 se modifica el Código Procesal Penal de la Provincia de San Juan (Ley No 7398), incorporando el Proceso Penal Juvenil.

El Proceso Penal Juvenil implementa como organismo especializado para conocer en materia de menores sometidos a un proceso penal juvenil, al Juez Penal de la Niñez y Adolescencia (art. 47 bis, CPP), a quien le corresponde, de modo exclusivo y excluyente, la investigación y juzgamiento de los hechos delictivos en los que aparezca involucrado un menor de edad al momento de su comisión, sea o no punible de acuerdo a la ley de fondo.

Si bien el Juez Penal de la Niñez y Adolescencia ejerce una doble función de investigación y juzgamiento, el ejercicio de la competencia de investigación excluye la de juicio.

Se establece que el Fiscal Penal de la Niñez y Adolescencia actuará, de modo exclusivo, ante los Jueces Penales de la Niñez y Adolescencia de acuerdo a lo establecido en el Código (art. 91 bis, CPP), como que los Defensores Penales de la Niñez y Adolescencia, ejercerán la defensa técnica del niño o adolescente que no tuviere asistencia letrada particular (art. 91 ter, CPP), y que el Asesor Penal de la Niñez y Adolescencia tendrá en el proceso penal de menores una intervención similar a la atribuida al defensor, aun cuando el imputado tuviere asistencia letrada, y durará hasta que el proceso concluya por cualquiera de las formas admitidas en el Código (art. 91 quáter, CPP).

Las medidas socioeducativas a aplicar a los niños o adolescentes, están previstas en el artículo 487 del CPP, y podrán consistir en: a) Entrega del niño o adolescente a sus padres, tutores o guardadores, bajo periódica supervisión; b) Tratamiento médico, psicológico o psiquiátrico, previo informe que acredite su necesidad; c) Inclusión del niño y su familia en programas de asistencia comunitarios; d) Inclusión o derivación a tratamientos por adicciones en instituciones oficiales o privadas; e) Alojamiento en entidades públicas o privadas de contención de niños; f) Medidas de guardas provisorias en la familia, familia ampliada o en familias de la comunidad; g) Adquisición de oficio, profesión o arte adecuado a su capacidad; h) Realización de tarea útil laboral; i) Realizar trabajos remunerados o no a favor de instituciones de la comunidad; ñ) Libertad asistida; j) Libertad vigilada; k) Régimen de semilibertad; 1) Alojamiento en un establecimiento especializado para niños y adolescentes; m) Servicios a la comunidad. Sin perjuicio de tal enumeración, se prevé que el Juez Penal de la Niñez y Adolescencia podrá dictar otras más adecuadas a la personalidad del niño o adolescente y a la naturaleza del hecho (art. 487, $5^{\circ}$ párrafo). 
La reforma contempla expresamente el principio de especialización exigido por las convenciones internacionales en cuanto a la materia, procedimientos, designación de magistrados y funcionarios judiciales (jueces, fiscales y defensores especializados), personal policial y profesionales de los organismos administrativos encargados de los centros especializados en que deberán cumplirse las medidas privativas de libertad. Pero como es necesario destinar recursos económicos para su implementación, se dispuso en el art. $3^{\circ}$ de la Ley 8194 que cuando las posibilidades financieras permitan la creación de los organismos previstos, la Corte de Justicia determinará la fecha de entrada en vigencia de la presente ley, que publicará en el Boletín Oficial y por acordada, asignará, sustraerá y reasignará competencias conforme a las necesidades de la especialización y/o servicio.

No se ha concretado hasta la fecha la entrada en vigencia de las disposiciones de la ley $\mathrm{N}^{\circ}$ 8194, cuando es urgente necesidad de adopción de normativa respecto a la justicia juvenil que respete los estándares internacionales de protección de los derechos de niños, niñas y adolescentes.

\section{LA JUSTICIA RESTAURATIVA}

La justicia restaurativa resume una filosofía alternativa basada en la restitución para hacer frente al delito, entendiendo que es necesario reparar el daño personal y social causado con el mismo. Permite también el abordaje del conflicto penal sin judicializarlo.

Se caracteriza por involucrar a la víctima como una parte indispensable dentro del proceso penal, y que cuenta con diversos métodos o prácticas que buscan la interacción entre el ofensor, la víctima, la comunidad y el Estado en un marco de igualdad y respeto por los derechos fundamentales $\left({ }^{24}\right)$.

La justicia restaurativa se centra en los efectos dañinos producidos por el delito e involucra activamente a las víctimas y los delincuentes, en el proceso de reparación y rehabilitación, y tres principios fundamentales guían su implementación: a) La justicia requiere que trabajemos a fin de que se ayude a volver a su estado original a aquéllos que se han visto perjudicados; b) De desearlo, aquéllos que se han visto más directamente involucrados o afectados por el delito, deben tener la posibilidad de participar de lleno en la respuesta; c) El rol del Gobierno consiste en preservar el justo orden público; la comunidad debe construir y mantener una justa paz $\left({ }^{25}\right)$.

No es un programa, ya que esos principios pueden aplicarse a diversos programas o prácticas que incluyan, principalmente, la reparación del daño, la reconstrucción de las relaciones rotas y la participación de todos los involucrados.

24 VAN NESS, Daniel W.; "Restoring Justice". Third Edition. EE.UU. 2006; citado por CARLOS BRENES QUESADA en "JUSTICIA RESTAURATIVA- Una herramienta para la solución al fenómeno de la criminalidad costarricense", San José, Costa Rica, Julio 2009. Disponible en: http://www.justiciarestaurativa.org/news/JUSTICIA\%20RESTAURATIVA-1\%20carlos.pdf

25 Justicia Restaurativa en línea. Disponible en: http://www.justiciarestaurativa.org/ 


\subsection{EL PAPEL DE LA JUSTICIA RESTAURATIVA EN ADOLESCENTES}

La aplicación de la Justicia Restaurativa a los adolescentes en conflicto con la ley penal es algo que se considera muy apropiado $\left({ }^{26}\right)\left({ }^{27}\right)\left({ }^{28}\right)$, tiene desarrollo en diversos países de América latina y el Caribe $\left({ }^{29}\right)\left({ }^{30}\right)\left({ }^{31}\right)$, y su implementación varía en función a los recursos locales, las tradiciones y culturas.

Proporcionan un contexto en el que los jóvenes pueden asumir la responsabilidad por sus acciones, y también es posible la restitución a las víctimas, de modo que los adolescentes en conflicto con la ley penal pueden tener una segunda oportunidad y ser reintegrados, y la armonía se pueda restaurar en la comunidad.

Señala Padilla que los programas de justicia restaurativa incluyen metodologías como la mediación víctima-ofensor, las conferencias de grupos familiares, los círculos de sentencia y las mesas comunitarias de reparación. Y entre las respuestas restaurativas se encuentran los servicios en beneficio de la comunidad, la reparación y la restitución, entre otras, siendo las medidas en comunidad las de mayor implementación y mejor valoración por parte de las víctimas, los ofensores, las comunidades y los operadores de los sistemas de justicia.

Indica que los bajos índices de reincidencia de los adolescentes que han participado en programas de justicia restaurativa $(12 \%)$, en comparación con los índices de reincidencia de quienes han sido privados de la libertad (75\%), han favorecido ampliamente su desarrollo mediante experiencias piloto que hoy se concretan en buenas prácticas susceptibles de ser replicadas $\left({ }^{32}\right)$.

26. LLOBET RODRÍGUEZ, Javier; "JUSTICIA RESTAURATIVA Y LA PROTECCIÓN DE LA VÍCTIMA". Disponible en: http://new. pensamientopenal.com.ar/sites/default/files/2011/o8/32llobet.pdf

27. KEMELMAJER DE CARLUCCI, Aída, "Justicia Restaurativa. Posible respuesta para el delito cometido por personas menores de edad", Ed. Rubinzal Culzoni Editores. Bs. As., Dic. 2009.

28. JUSTICIA RESTAURATIVA EN EL SISTEMA DE RESPONSABILIDAD PENAL JUVENIL: CONCEPTOS, PERSPECTIVAS Y MECANISMOS PROCESALES PARA SU IMPLEMENTACIÓN, Publicación de la Secretaría de Derechos Humanos, Primera edición: enero de 2010, 208 páginas. Disponible en: http://www.derhuman.jus.gov.ar/publicaciones/pdfs/21-dhpn-Dispositivos_no_ privativos_de_libertad.pdf

29. CÁMARA ARROYO, Sergio; "JUSTICIA JUVENIL RESTAURATIVA: MARCO INTERNACIONAL Y SU DESARROLLO EN AMÉRICA LATINA", Revista de Justicia Restaurativa, ISSN 2174-86o8. Disponible en: http://usecmagazine.usecnetwork.com/ files/2011/12/JUSTICIA-RESTAURATIVA-AMERICA-LATINA.pdf

3o. PADILLA, Andrea; "Justicia restaurativa y Sistema de Responsabilidad Penal para Adolescentes". Disponible en: http://www. srpa.org/2010/12/15/justicia-restaurativa-y-sistemas-de-responsabilidad-penal-para-adolescentes/.

31. CORREA GARCIA, Sergio; “Diferentes Instrumentos y Modelos de Justicia de Menores”. Disponible en: http://www.bibliojuridica. org/libros/6/2680/14.pdf

32. PADILLA, Andrea; cit. en nota 31. 
En Argentina existen nueve Jurisdicciones que prevén la mediación penal: Ciudad Autónoma de Buenos Aires $\left({ }^{33}\right)$ y provincias de Chaco, Chubut, La Rioja, Mendoza $\left({ }^{34}\right)$, Neuquén $\left({ }^{35}\right)$, Buenos Aires, Río Negro y Santa Fe $\left(^{36}\right)\left({ }^{37}\right)\left({ }^{38}\right)$.

\subsection{LAS CORTES PARA ADOLESCENTES (TEEN COURTS)}

Los Tribunales para Adolescentes se están expandiendo rápidamente en los Estados Unidos de Norteamérica, como una alternativa y/o complemento al sistema de justicia juvenil para los jóvenes que han cometido delitos no violentos, pasando de 78 programas en 1994 a que existan más de 1.050 programas de los tribunales juveniles en operación en 49 estados y el Distrito de Columbia, desde marzo de $2010\left({ }^{39}\right)$.

Las Corte de Adolescentes es un programa que ofrece a los adolescentes en conflicto con la ley penal una segunda oportunidad, para aprender de su error, sin el alto costo y el estigma de quedar con antecedentes penales $\left({ }^{40}\right)\left({ }^{41}\right)\left({ }^{42}\right)$.

Estas Cortes Juveniles, también conocidas como Tribunales para Adolescentes y Jurados de Pares (Juries of Peers), involucra a los voluntarios de 14 a 18 años de edad en la sentencia de sus pares por delitos no violentos como tirar basura, robo, alteración del orden público, llevar un arma oculta, etc. $\left({ }^{43}\right)$.

Los jóvenes voluntarios también están expuestos a una nueva forma de pensar la justicia, lo que aumenta la experiencia educativa que los Tribunales de Adolescentes les pueden proporcionar, incrementa su conciencia sobre los efectos de la delincuencia y les facilita el desarrollo de su empatía hacia los demás.

33. LEY 2451 - Régimen procesal penal juvenil de la Ciudad Autónoma de Buenos Aires (B.O. 13/11/2007-ADLA 2008 - A, 440).

34. Proyecto Piloto de Mediación Penal Juvenil en la Provincia de Mendoza, en aplicación del art. 61 de la Ley 6354 de Protección Integral del Niño y el Adolescente.

35. DEMIZ, Graciela Isabel; "La imposición de pena en la Justicia Penal Juvenil. Con especial referencia a la provincia de Neuquén”, LLPatagonia 2011 (abril), 123. Indica que en el marco de este programa se ha logrado la firma de numerosos acuerdos víctimavictimario, participando de los mismos los padres de los menores involucrados y en ocasiones alguna institución (por ejemplo, un representante del centro educativo cuando el conflicto tuvo origen o vinculación con una cuestión del ámbito escolar). Agrega que los casos sometidos a mediación son de delitos leves, sin violencia grave sobre las personas: daños, amenazas, lesiones leves y culposas, robos y hurtos, y que el promedio de acuerdos (aproximadamente 70 \%) y la poca reincidencia permite concluir que este programa ha dado excelentes resultados en la provincia de Neuquén.

36. MECANISMOS DE JUSTICIA RESTAURATIVA Y NORMATIVA PROCESAL, en Publicación de la Secretaría de Derechos Humanos cit. en nota 29.

37. CORREA GARCIA, Sergio; obra cit. en nota 32.

38. Ver SOLER ROQUE, María del Rosario y LÓPEZ, Ana Laura; "Mesa de Debate: "Mecanismos de justicia restaurativa en los nuevos sistemas penales juveniles", en AVANCES Y DESAFÍOS DE UN SISTEMA PENAL JUVENIL EN CONSTRUCCIÓN. Disponible en: http://www.unicef.org/argentina/spanish/SISTEMA_PENAL_JUVENIL_baja.pdf. La segunda de las citadas indica "Nos dimos cuenta de que no existían en términos generales - a nivel país-, mecanismos de justicia restaurativa, salvo honrosas y muy destacables experiencias en algunos ámbitos locales".

39. Información disponible en: $h t t p: / / w w w . y o u t h c o u r t . n e t / ? p a g e \_i d=559$.

40. Información disponible en: http://www.aacounty.org/Police/teenCourt.cfm.

41. Habiendo participado como becario seleccionado por la Embajada de EEUU en Argentina del programa "Administration of Justice and the Rule of Law", en el año 2009, tuve la oportunidad de intervenir como observador en el desarrollo de algunas audiencias en las que adolescentes eran juzgados por sus propios pares en la Corte Juvenil (Teen Court) de Indianápolis.

42. Una Corte Juvenil específica es la Corte Juvenil de Drogas. Ver a Hoyt, Joshua D., "Juvenile Drug Court: Predictors of Graduation and Non-Graduation Status" (2012). All Graduate Theses and Dissertations. Paper 1294. Disponible en: http://digitalcommons.usu. edu/etd/1294.

43. Información disponible en: http://www.cgpolice.org/peer.htm. 
En lugar de ser ignorados por el sistema de justicia juvenil por un delito menor, o de solo pagar una multa, la juventud frente a la Corte responde y aborda el impacto de su comportamiento en todas las víctimas. En cada caso, los jóvenes tienen la oportunidad de asumir la responsabilidad, rendir cuentas, y compensar el daño que han causado.

De acuerdo con la base de datos de la National Youth Court: el 93\% de los programas de corte juvenil en los EE.UU. requieren a los jóvenes a admitir su culpabilidad antes de participar en el tribunal de menores; En el 7\% de los programas de los tribunales juveniles que permitan a los jóvenes a declararse "no culpable"; si un joven decide declararse "no culpable", el programa lleva a cabo una audiencia para determinar la culpabilidad o inocencia. Cuando los acusados completan con éxito un programa de la Corte Juvenil, el 63\% de los Tribunales de Menores desestima los cargos, y el menor no registra ningún antecedente penal $\left({ }^{44}\right)$.

Los Tribunales de Menores tienen un costo muy inferior, en comparación con el sistema de justicia tradicional, $\mathrm{y}$ han obtenido como resultado la reducción de las tasas de reincidencia $\left({ }^{45}\right)$.

Resulta así una estrategia efectiva para reducir la delincuencia juvenil, permitiendo a los jóvenes asumir su responsabilidad por sus acciones, en beneficio de sus comunidades, y para aprender cómo funciona el sistema judicial.

\subsection{LOS JUICIOS POR JURADOS EN ARGENTINA}

Si bien hay quienes consideran que su puesta en práctica requiere del dictado de una ley por parte del Parlamento Nacional que regule el sistema de jurados para toda la Nación, sea que se trate de tribunales federales como provinciales $\left({ }^{46}\right)$, compartimos la opinión de quienes sostienen que las provincias, en ejercicio de su autonomía constitucional, pueden incluirlos en la organización de su administración de justicia $\left({ }^{47}\right)$.

Ocho Constituciones provinciales los incluyen como parte de la organización de los tribunales provinciales (Córdoba, Santiago del Estero, San Luis, Corrientes, Río Negro, Entre Ríos, La Rioja y Chubut), a lo que debe agregarse la Ciudad Autónoma de Bs. As. $\left({ }^{48}\right)$.

Si bien la única provincia que reglamentó el juicio por jurados es Córdoba, la provincia de Neuquén dictó en diciembre de 2011 la ley que implementa el juicio por jurados en su forma clásica o tradicional, y prevé su entrada en vigencia a partir de enero de 2014. Existen también proyectos legislativos para implementarlo en la nación y en varias provincias argentinas $\left({ }^{49}\right)$.

\section{CONCLUSIÓN}

Señalaba el Maestro Morello que:

\footnotetext{
44. Información disponible en: http://www.youthcourt.net/. 45. Información disponible en: http://www.urban.org/uploadedpdf/410457.pdf.

46. QUIROGA LAVIÉ, Humberto; "Constitución de la Nación Argentina comentada, Ed. Zavalía, pág. 394.

47. DÍAZ RICCI, Sergio; "El juicio por jurados es atribución provincial", LLNOA 2011 (diciembre), 1161.

48. DÍAZ RICCI, Sergio; obra cit.

49. GRANILLO FERNÁNDEZ, Héctor; "LA HORA DE LA JUSTICIA REPUBLICANA: ES INMINENTE LA INSTAURACIÓN DEL JUICIO POR JURADOS EN VARIAS PROVINCIAS Y EN EL ORDEN NACIONAL DE LA ARGENTINA". Disponible en: http://new. pensamientopenal.com.ar/sites/default/files/2012/04/procesoso3.pdf.
} 
"No es fácil -y casi nunca exitoso- propiciar forzadamente el trasplante de instituciones arraigadas en un país a lo largo de fuentes históricas propias, de una cultura jurídica de rasgos singulares, con una maciza forja de precedentes, de hábitos y costumbres (también valores y creencias fuertemente concientizadas), a otro medio socio económico cultural cuyo torso no se identifica suficientemente con aquél. Sin prejuicios ni prevenciones, la experiencia del jurado es interesante y debemos considerarla con atención y en todo caso con recepción gradual y para determinados asuntos. Pero no plantarnos en un no carente de razonabilidad" $\left({ }^{50}\right)$.

Entendemos que es la justicia penal juvenil, por sus especialidades y características, un excelente marco para incluir los programas y mecanismos reparadores que insta el sistema de justicia restaurativa $\left({ }^{51}\right)$.

Las Cortes o Tribunales Juveniles permiten a los adolescentes tener una "segunda oportunidad", asumiendo la responsabilidad por el daño causado ante las víctimas de delitos no violentos, reparando a la víctima y a la comunidad, como también disminuyendo sensiblemente el índice de reincidencia en el delito. No solo se logra reintegrar al adolescente en la sociedad, sino que también permitiría convertir a los adolescentes que participan como jurados voluntarios - gracias a ese rol social participativo- en mejores ciudadanos, facilitando la posterior implementación de juicios por jurados para juzgar delitos cometidos por personas adultas.

Pueden contribuir a que exista un sistema judicial más eficaz y más humano, en donde tanto adolescentes en conflicto con la ley penal, así como adolescentes víctimas de delitos no violentos, tengan acceso a la justicia de manera más satisfactoria y den solución a sus conflictos de acuerdo con sus valores, principios e intereses.

Por ello proponemos incluir como una vía diferente del sistema penal tradicional, sin sustituirlo, a la opción voluntaria que permita a los adolescentes en conflicto con la ley, que han cometido por primera vez un delito no violento y reconocen su responsabilidad, a ser juzgados por sus pares a cambio de la extinción de la acción penal cuando cumplan con el veredicto. $\mathrm{Y}$ ante los nuevos requerimientos jurídicos y sociales, resulta perentorio la capacitación de expertos en justicia penal restaurativa, como que los procedimientos que comprende esta corriente del derecho penal se apliquen con el fin de lograr la reinserción social del menor en conflicto con la ley penal.

\section{BIBLIOGRAFÍA}

- CÁMARA ARROYO, Sergio; "Justicia Juvenil Restaurativa: Marco Internacional y su desarrollo en América Latina", Revista de Justicia Restaurativa, ISSN 2174-8608.

- DE LA IGLESIA, Matilde; VELÁZQUEZ, María Eugenia; PIEKARZ, Walter; 'Devenir de un cambio: Del patronato de menores a la protección integral de los derechos de niños, niñas y adolescentes", Facultad de Psicología - UBA / Secretaría de investigaciones / Anuario de investigaciones / Volumen XV.

- DEMIZ, Graciela Isabel; “La imposición de pena en la Justicia Penal Juvenil. Con especial referencia a la provincia de Neuquén", LLPatagonia 2011.

50. MORELLO, Augusto M.; "Crónica de una experiencia judicial [el jurado] en Miami”, LA LEY 1997-F, 1418

51. Una política criminal que en lo relativo al tratamiento de niños, niñas y adolescentes infractores esté orientada meramente por criterios retributivos, y deje en un segundo plano aspectos fundamentales como la prevención y el fomento de oportunidades para una efectiva reinserción social, sería incompatible con los estándares internacionales en materia de justicia penal juvenil. C $f$ r. informe 172/10 de la CIDH (párrafo 146). 
- DÍAZ RICCI, Sergio; "El juicio por jurados es atribución provincial”, LLNOA 2011 (diciembre), 1161.

- GRANILLO FERNÁNDEZ, Héctor; "La hora de la Justicia Republicana: Es inminente la instauración del juicio por jurados en varias provincias y en el orden nacional de la Argentina". Disponible en: http://new.pensamientopenal.com.ar/sites/default/files/2012/04/ procesos03.pdf.

- HOYT, Joshua D., "Juvenile Drug Court: Predictors of Graduation and Non-Graduation Status" (2012). All Graduate Theses and Dissertations. Paper 1294. Disponible en: http:// digitalcommons.usu.edu/etd/1294

- JUSTICIA RESTAURATIVA EN EL SISTEMA DE RESPONSABILIDAD PENAL JUVENIL: CONCEPTOS, PERSPECTIVAS Y MECANISMOS PROCESALES PARA SU IMPLEMENTACIÓN, Publicación de la Secretaría de Derechos Humanos, Primera edición: enero de 2010.

- KEMELMAJER DE CARLUCCI, Aída, "Justicia Restaurativa. Posible respuesta para el delito cometido por personas menores de edad", Ed. Rubinzal Culzoni Editores. Bs. As., 2009.

- LLOBET RODRÍGUEZ, Javier; "Justicia Restaurativa y la Protección de la Víctima". Disponible en: http://new.pensamientopenal.com.ar/sites/default/files/2011/08/32llobet. pdf.

- MORELLO, Augusto M.; “Crónica de una experiencia judicial [el jurado] en Miami”, LA LEY 1997-F, 1418.

- PADILLA, Andrea; "Justicia restaurativa y Sistema de Responsabilidad Penal para Adolescentes". Disponible en: http://www.srpa.org/2010/12/15/ justicia-restaurativa-y-sistemas-de-responsabilidad-penal-para-adolescentes/.

- PRATEEK, Shukla; "The Criminal Child and its Potential for Change: A Presumption in Favor of Rehabilitation in Sentencing Juvenile Offenders", New England School of Law, 2012, N.E. J. on Crim. \& Civ. Con. 379.

- QUINN, Mae C.; "Introduction: Evolving Standards in Juvenile Justice from Gault to Graham and Beyond", 38 Wash. U. J. L. \& Pol'y 1 (2012).

- QUIROGA LAVIÉ, Humberto; "Constitución de la Nación Argentina comentada, $3^{\circ}$ edición, Ed. Zavalía, Bs. As., 2000.

- SOLER ROQUE, María del Rosario y LÓPEZ, Ana Laura; "Mesa de Debate: "Mecanismos de justicia restaurativa en los nuevos sistemas penales juveniles", en AVANCES Y DESAFÍOS DE UN SISTEMA PENAL JUVENIL EN CONSTRUCCIÓN. Disponible en: http:// www.unicef.org/argentina/spanish/SISTEMA_PENAL_JUVENIL_baja.pdf.

- VAN NESS, Daniel W.; "Restoring Justice", Third Edition, EE.UU, 2006; citado por CARLOS BRENES QUESADA en "JUSTICIA RESTAURATIVA- Una herramienta para la solución al fenómeno de la criminalidad costarricense", San José, Costa Rica, Julio 2009.

- ZAFFARONI, Eugenio Raúl - ALAGIA, Alejandro - SLOKAR, Alejandro; "Derecho Penal, Parte General", Editorial Ediar, Buenos Aires, 2003, p. 187. 